\title{
Inconsistencies in a study of the relationship between sleep disorders, mental health, and gaming behaviour in Africa
}

Etchells, P.J. Department of Psychology, School of Sciences, Bath Spa University, Newton Park, Newton St Loe, Bath, UK. p.etchells@,bathspa.ac.uk

Brown, N.J.L. Linnaeus University, Växjö, Sweden. nicholas.brown@lnu.se

Heathers, J.A.J. Bouvé College of Health Sciences, Northeastern University, Boston MA 02115.jamesheathers@gmail.com

Przybylski, A.K. Oxford Internet Institute, Department of Experimental Psychology, University of Oxford andy.przybylski@,oii.ox.ac.uk

\section{Competing interests statement}

The authors declare no competing interests. AKP is currently supported by a grant from the Huo Family Foundation.

\section{Author contributions statement}

All authors made substantial contributions to the first draft and subsequent edits of the paper. All authors approved the final manuscript.

In 2018, the World Health Organisation included Gaming Disorder as a new diagnostic category in the upcoming International Classification of Diseases (ICD-11; WHO, 2018). This decision was controversial among video game effects researchers (Van Rooij et al., 2018), as it was argued that methodologies and scientific standards in this area were of insufficient quality to determine a consensus about the nature of such a disorder. Further, most data collected on gaming and its health effects have been focused on North American, European, and Asian populations. Given that Africa has approximately half a billion mobile phone subscribers (Pendergrass et al., 2019) and a growing adolescent population of which an estimated 14\% have mental health problems (Cortina et al., 2012), it is urgent that highquality research is conducted that addresses the potential associations between video game use and mental health in this population. Etindele Sosso and colleagues (2020; hereafter referred to as the published paper) report the results of a large-scale study surveying players from nine African countries, a first as far as we are aware. We were surprised to read that almost one in three participants met the diagnostic criteria for gaming disorder, a rate ten times higher than meta-analytic estimates (Ferguson, Coulson and Barnett, 2011), and that $86.9 \%$ of observed variability in reported insomnia was accounted for by gaming behaviour. However, we are concerned that numerous issues in this article warrant further scrutiny, related to: (1) data provenance, (2) data inconsistencies, (3) data similarities, and (4) statistical errors. Together, these issues call into question the accuracy of the findings, and their implications for our understanding of gaming effects.

The first issue concerns the data's provenance. The published paper reports data from 10,566 respondents (mean age $24+/-2.8$ years, $11.36 \%$ women) sampled from an initial 53,634. These demographics are remarkably similar to an earlier preprint (hereafter preprint 1) made available online, but not cited, by the first two authors of the published study (Etindele Sosso and Kuss, 2018), which describes an ostensibly different study of the relationship between 
insomnia and gaming, using different predictors and outcomes. In preprint 1 , data are taken from 10,566 respondents from an initial pool of 120,460 (11.36\% women). The sample reported in the abstract and methods has a mean age of $24+/-2.8$ years, although it is not clear whether this relates to the initial pool or final sample (a mean age of $22.33+/-2$ years is later reported in the results). There are reasons to believe the data in the published paper and preprint 1 are based on the same sample. First, recruiting 174,094 participants across nine countries represents a substantial undertaking and we are unaware of such studies being described elsewhere. Second, the published paper is described as a secondary analysis of previously-collected data. Third, there is a high degree of similarity in the wording of both papers - $80 \%$ of the sentences in the introduction and $\sim 50 \%$ of the sentences in the discussion in the published paper match those found in preprint 1 . It would be reasonable to assume these papers are based on the same sample, but the degree of overlap between the data reported in the published paper and preprint 1 remains unknown.

The second, related issue concerns inconsistencies between measures reported in the published paper and preprint 1. Across demographics and technology use, data are identical in some cases, but not others. As our Table 1 shows, a comparison of Table 2 in the published paper with Tables 1 and 2 in preprint 1 reveals that the studies yield exactly the same numbers of participants for 18 out of 36 combinations of country of residence and technology type. A further 7 combinations yield numbers for which the final two digits match. It is unclear how identical data could be reported if the two studies are based on different samples, or why there are key differences between the two if they are drawn from the same sample. This issue raises serious concerns about whether the data collection procedures reported in these studies are accurate, and how the descriptive statistics were generated. 


\begin{tabular}{|c|c|c|c|c|c|c|c|c|c|c|}
\hline Country & $\begin{array}{l}\text { Published } \\
\text { Total }\end{array}$ & $\begin{array}{c}\text { Preprint } \\
1 \text { Total }\end{array}$ & $\begin{array}{c}\text { Published } \\
\text { Gamers using } \\
\text { smartphones }\end{array}$ & $\begin{array}{c}\text { Preprint } 1 \\
\text { Gamers using } \\
\text { smartphones }\end{array}$ & $\begin{array}{l}\text { Published } \\
\text { Gamers } \\
\text { using } \\
\text { tablets }\end{array}$ & $\begin{array}{c}\text { Preprint } \\
1 \\
\text { Gamers } \\
\text { using } \\
\text { tablets }\end{array}$ & $\begin{array}{l}\text { Published } \\
\text { Gamers } \\
\text { using } \\
\text { computers }\end{array}$ & $\begin{array}{l}\text { Preprint } 1 \\
\text { Gamers } \\
\text { using } \\
\text { computers }\end{array}$ & $\begin{array}{c}\text { Published } \\
\text { Gamers } \\
\text { using } \\
\text { consoles }\end{array}$ & $\begin{array}{c}\text { Preprint } \\
1 \\
\text { Gamers } \\
\text { using } \\
\text { consoles }\end{array}$ \\
\hline $\begin{array}{l}\text { South } \\
\text { Africa }\end{array}$ & 2580 & 2200 & 1500 & 1500 & 94 & 14 & 800 & 600 & 186 & 86 \\
\hline Cameroon & 1456 & 1306 & 700 & 700 & 63 & 13 & 286 & 186 & 407 & 407 \\
\hline $\begin{array}{l}\text { Ivory } \\
\text { Coast }\end{array}$ & 908 & 850 & 230 & 230 & 58 & 0 & 520 & 520 & 100 & 100 \\
\hline Gabon & 449 & 500 & 153 & 153 & 217 & 217 & 62 & 113 & 17 & 17 \\
\hline Morocco & 1831 & 1100 & 950 & 450 & 41 & 41 & 689 & 489 & 151 & 120 \\
\hline Nigeria & 1298 & 1310 & 456 & 456 & 83 & 83 & 605 & 617 & 154 & 154 \\
\hline Rwanda & 897 & 710 & 371 & 271 & 18 & 18 & 316 & 229 & 192 & 192 \\
\hline Sénégal & 846 & 1090 & 387 & 387 & 7 & 7 & 366 & 653 & 86 & 43 \\
\hline Tunisia & 301 & 1500 & 100 & 800 & 26 & 26 & 94 & 480 & 81 & 194 \\
\hline
\end{tabular}

Table 1: A comparison of descriptive statistics relating to type of technology use across countries as reported in Table 2, Etindele Sosso et al. (2020) and Table 2, Etindele Sosso \& Kuss (2018). Red numbers denote exact matches across the two studies. Blue numbers denote matches for the final two digits. 
The third issue concerns similarities in shared outcomes across the published paper and preprint 1 and a third piece of writing. Although based on ostensibly different samples, data on the Insomnia Severity Index (ISI) are identical in both the published paper and preprint 1: "The internal consistency of the ISI was excellent (Cronbach's $\alpha=0.92)$, and each individual item showed adequate discriminative capacity $(r=0.65-0.84)$. The area under the receiver operator characteristic curve was 0.87 and suggested that a cut-off score of 14 was optimal (82.4\% sensitivity, $82.1 \%$ specificity, and $82.2 \%$ agreement) for detecting clinical insomnia." This exact wording also appears in a further preprint by Etindele Sosso (2019). This is a completely different study based on a sample of 1,238 Canadian customer service employees. It is unclear how these same scores could have been achieved.

The fourth issue concerns apparent statistical reporting errors in Etindele Sosso et al.'s (2020) analysis. Within the 68 reported rows in Table 3 of the published paper:

- The ratio between the unstandardized regression coefficient (column "B") and the standard error (column "SE") never matches the corresponding $t$ statistic (column " $t$ "), even allowing for substantial rounding error;

- Similarly, the ratio between the standardized regression coefficient (column " $\beta$ ") and the standard error does not match column " $t$ ";

- The $p$ value (column "Sig.") does not match the $t$ statistic;

- Often, the $p$ value does not have the same relation to the conventional threshold for "statistical significance" (either side of .05) as the $t$ statistic does to the equivalent threshold (either side of $\sim 1.96$ ). In $\sim 50 \%$ of rows, the regression coefficients are not within the corresponding $95 \%$ confidence intervals (CI);

- Coefficients for the "Age" category 42-48 and "Education" category "Postdoctorate" are non-zero in all four models, although there are zero participants in these categories (Table 1 of the published paper).

Together, these problems call into doubt the results and conclusions of the study.

The WHO's decision to include Gaming Disorder in ICD-11 has raised the reputational stakes for researchers, practitioners, and policymakers focused on gaming and health. Higher stakes should be accompanied by greater scrutiny as we close gaps in our knowledge. It is in this spirit that we closely read Etindele Sosso et al. (2020); in doing so, we discovered a curious range of inconsistencies, which inform our serious concerns about the veracity of the results. It is noteworthy that this work passed peer review and has been cited with these issues going unrecognised (King, Billieux, Carragher, and Delfabbro, 2020).

Given the gravity of the WHO's Gaming Disorder decision, we strongly believe work on this topic must adhere to the principles of Open Science: hypotheses and analysis protocols must be pre-registered, with supporting data and analysis code made freely available during review (Morey et al., 2016) and at the time of publication (Munafò et al., 2017) ${ }^{1}$. It is only by

1 Data from two of the nine countries have been made available at https://data.mendeley.com/datasets/c53rh2h435/1, but these raise even more questions. For example, the correlations between the four outcome variables for Gabon range from 0.994 to 1.000. Moreover, the data concerning smartphone use appear to be exactly the same for the 301 Tunisian respondents and the first 301 from Gabon. 
demanding the most robust, best-practices approaches to science that we can avoid unreliable results further clouding academic discussion of gaming effects in the future.

\section{References}

Cortina, M. A., Sodha, A., Fazel, M., \& Ramchandani, P. G. Prevalence of child mental health problems in sub-Saharan Africa: A systematic review. Arch Pediatr Adolesc Med. 166, 276-281 (2012).

Etindele Sosso, F. A. Insomnia, excessive daytime sleepiness, anxiety, depression and socioeconomic status among customer service employees in Canada. Preprint at https://www.medrxiv.org/content/10.1101/19003194v1 (2019).

Etindele Sosso, F. A., \& Kuss, D. J. Insomnia and problematic gaming: a study in 9 low-and middle-income countries. Preprint at https://www.biorxiv.org/node/136254. full (2018).

Etindele Sosso, F. A. et al. Insomnia, sleepiness, anxiety and depression among different types of gamers in African countries. Sci Rep. 10, 1-12 (2020).

Ferguson, C. J., Coulson, M., \& Barnett, J. A meta-analysis of pathological gaming prevalence and comorbidity with mental health, academic and social problems. J Psychiatr Res. 45, 1573-1578 (2011).

King, D. L., Billieux, J., Carragher, N., \& Delfabbro, P. H. Face validity evaluation of screening tools for gaming disorder: Scope, language, and overpathologizing issues. J Behav Addict. 9, 1-13 (2020).

Morey, R. D. et al. The Peer Reviewers' Openness Initiative: incentivizing open research practices through peer review. R Soc Open Sci. 3, 150547 (2016).

Munafò, M. R. et al. A manifesto for reproducible science. Nat Hum Behav. 1, 1-9 (2017).

Pendergrass, T. M., Hieftje, K., \& Fiellin, L. E. Improving Health Outcomes and Quality of Life for African Adolescents: The Role of Digital and Mobile Games in Handbook of Quality of Life in African Societies (ed. Eloff, I.) 149-176 (Springer, 2019).

Van Rooij, A. J. et al. A weak scientific basis for gaming disorder: Let us err on the side of caution. J Behav Addict. 7, 1-9 (2018).

World Health Organisation. Gaming Disorder. https://www.who.int/news-room/q-adetail/gaming-disorder (2018). 